\title{
A sensitive colorimetric biosensor based on intermolecular split G-quadruplex DNAzymes and magnetic nanoparticles for the detection of $\mathrm{Hg}^{2+}$
}

\author{
Wei Zhang, Yujiao Tang, Shuang Shao, Shiyan Dai, Guifang Cheng*, Pingang He, and Yuzhi Fang \\ Department of Chemistry, East China Normal University, Shanghai 200241, PR China
}

\begin{abstract}
In this paper, we report a novel and sensitive optical sensing protocol for the detection of mercury (II) ions based on colorimetry combined with intermolecular split G-quadruplex DNAzymes and the conjugation of thymine- $\mathrm{Hg}^{2+}$-thymine. A T-rich strand A was assembled onto the biomagnetic beads. Two other oligonucleotide strands (strands B and C) were employed, which are each composed of a capture segment (T-rich part) and a sensing segment (G-rich part). In the presence of $\mathrm{Hg}^{2+}$, the capture segments of both strands $\mathrm{B}$ and $\mathrm{C}$ can hybridise with biotin-strand $\mathrm{A}$ on magnetic beads to form the stable DNA duplexes through $\mathrm{T}-\mathrm{Hg}^{2+}-\mathrm{T}$ linkages. The formation of the DNA duplex brings the sensing segments of both strands B strand C close enough to constructed an intermolecular split G-quadruplex. This split G-quadruplex is able to effectively catalyse the $\mathrm{H}_{2} \mathrm{O}_{2}$-mediated oxidation of ABTS in the presence of hemin, generating the blue-green product ABTS+ and increasing the absorption signal at $421 \mathrm{~nm}$. Therefore, the change in the absorption signal at $421 \mathrm{~nm}$ can be used to monitor the concentration of $\mathrm{Hg}^{2+}$. The calibration curve of the assay was linear over the range of $\mathrm{Hg}^{2+}$ concentrations from 2 to $50 \mathrm{nM}$, and the detection limit was $0.8 \mathrm{nM}$. Moreover, the influence of the intermolecular split G-quadruplex DNAzyme strands on the catalytic ability is also discussed. The practical results obtained imply that the proposed colorimetric biosensor can be extended for the detection of trace $\mathrm{Hg}^{2+}$ in environmental water and drinking water.
\end{abstract}

\section{Introduction}

The mercury ion $\left(\mathrm{Hg}^{2+}\right)$ is one of the most well-known widespread environmental pollutants and has distinct toxicological profiles that can cause deleterious effects on human health and the environment, even at low concentrations, as well as posing a challenge to the global plan of maintaining a sustainable environment [1,2]. Water-soluble $\mathrm{Hg}^{2+}$ is one of the most usual and stable forms of mercury contamination due to its high toxicity and bioaccumulation, and the $\mathrm{Hg}^{2+}$ pollution of water sources is serious in many countries and regions[3]. Once it enters into water sources and the bacteria turn it into an organic form, mercury can accumulate in organisms, eventually being ingested by humans through the food chain, which may affect their immune systems, enzyme systems, and damage their nervous systems, result in kidney failure, acrodynia and minamata disease. Therefore, routine testing for trace amounts of $\mathrm{Hg}^{2+}$ with excellent selectivity and sensitivity is important for water pollution control and drinking water safety.

Traditional analysis methods for the detection of $\mathrm{Hg}^{2+}$ in water samples include cold vapour atomic fluorescence spectrometry (CVAFS) [4], cold vapour atomic absorption spectroscopy (CV-AAS) [5], inductively coupled plasma mass spectroscopy (ICP-MS)[6] and so on. Although these methods are highly sensitive, stable, selective, and usually have DRs (Detected range of signal) of more than 4-5 orders of magnitude, they usually involve sophisticated instruments, skilled personnel, and complicated harmful sample pre-treatment methods. A colorimetric system has been introduced because of its stability and better ability to be controlled. However, its low sensitivity cannot meet the requirement for $\mathrm{Hg}^{2+}$ detection in drinking water.

Recently, many mercury ion sensors based on colorimetry combined with the DNAzymes and the conjugation of thymine- $\mathrm{Hg}^{2+}-$ thymine have been proposed to overcome these limitations [7-10]. The use of strands plentiful in thymine (as the recognising element) and DNAzymes (as the sensing element) is beneficial to colorimetric mercury ion sensors allowing harmful pre-treatments to be avoided and an improved detection sensitivity to be achieved. In our previous work, we have used the intramolecular split DNAzyme as catalyzer to contribute $\mathrm{Hg}^{2+}$ sensor [11]. In contrast with intramolecular split G-quadurplex DNAzyme, the intermolecular split DNAzymes, which are composed of two strands of DNA, could decrease background and make the design of strategy more flexible [12, 13]. However, it is reported that the catalytic capability of split DNAzymes is closely related to the base sequences of the DNAzyme strands [14]. That is to say, the characteristics of the split DNAzyme strands, such as their sequences, lengths and patterns of assembly are related to the sensitivity and selectivity of the assay, and therefore, all of these characteristics should be seriously discussed and well-designed $[15,16]$.

Herein, we proposed a new colorimetric biosensor based on intermolecular split G-quadruplex DNAzymes for the detection of mercury ions. In addition, magnetic nanoparticles (MNPs) are used as carriers of the recognising strands in our assay to remove other co-existing interfering ions through magnetic separation due to their

Correspondence to: Guifang Cheng, Department of Chemistry, East China Normal University, Shanghai 200241, PR China

Key words: magnetic nanoparticles, intermolecular split G-quadruplex DNAzymes, mercury ions, thymine-Hg2+-thymine

Received: November 29, 2016; Accepted: December 16, 2016; Published: December 19, 2016 
good biocompatibility, easy handling, and ability to minimise the background. As illustrated in Scheme 1, the T-rich A strands (modified with a biotin group at the 5 ' end) were assembled onto streptavidincoated MNPs. Two other oligonucleotide strands (strands B and C) were also used. These two strands are each composed of a capture segment and a sensing segment. The capture segment (marked as the red and purple parts in Scheme 1) is the T-rich segment to catch $\mathrm{Hg}^{2+}$ by forming the $\mathrm{T}-\mathrm{Hg}^{2+}-\mathrm{T}$ base pair, while the sensing segment (marked as the blue and yellow parts in Scheme 1) is the G-rich part that can form a catalytically active G-quadruplex in the presence of hemin. Therefore, in the presence of $\mathrm{Hg}^{2+}$, the capture segments of SB and SC can each hybridise with SA to form a stable DNA duplex by $\mathrm{T}-\mathrm{Hg}^{2+}-\mathrm{T}$ linkages. The formation of the DNA duplex makes the G-rich parts of SB and SC in close contact with each other, and a split Gquadruplex can be constructed, which is able to effectively catalyse the $\mathrm{H}_{2} \mathrm{O}_{2}$-mediated oxidation of ABTS in the presence of hemin, generating the blue-green coloured product $\mathrm{ABTS}^{+}$and increasing the absorption signal at $421 \mathrm{~nm}$. Hence, the change in the absorption signal at $421 \mathrm{~nm}$ can be applied to monitor the formation of the G-quadruplex structure, which is closely related to the $\mathrm{Hg}^{2+}$ concentration.

\section{Experimental}

\section{Reagents and apparatus}

All of the oligonucleotides purified by HPLC were synthesised by the Shanghai Sangon Biotechnology Co., Ltd. (Shanghai, China), and their sequences are listed in Table 1. Streptavidin-coated magnetic nanoparticles (MNPs) were obtained from Chemicell $\mathrm{GmBH}$ (Germany). Dimethyl sulfoxide (DMSO), Triton X-100, 30\% $\mathrm{H}_{2} \mathrm{O}_{2}$ and hemin were purchased from Sigma Chemical Co. (Shanghai, China). Tris-(hydroxymethyl) aminomethane hydrochloride (Tris- $\mathrm{HCl}$ ) and ABTS were purchased from the Shanghai Sangon Biotechnology Co., Ltd (Shanghai, China). 4-(2-Hydroxyethyl) piperazine-1ethanesulfonic acid (HEPES) was obtained from the Bio Basic Co. (Canada). Bovine serum albumin (BSA) was purchased from New England Biological Technology Co., Ltd. (Beijing, China).

An HZQ-C thermostatic shaker (Donglian Electrical Technology Co., Ltd., China) was used to assemble the oligonucleotide strands onto the surfaces of the MNPs. Colorimetric measurements were performed on a Cary 50 UV-visible spectrophotometer (Varian, Palo Alto, USA). $\mathrm{CD}$ experiments were performed on a JASO J-815 spectropolarimeter.

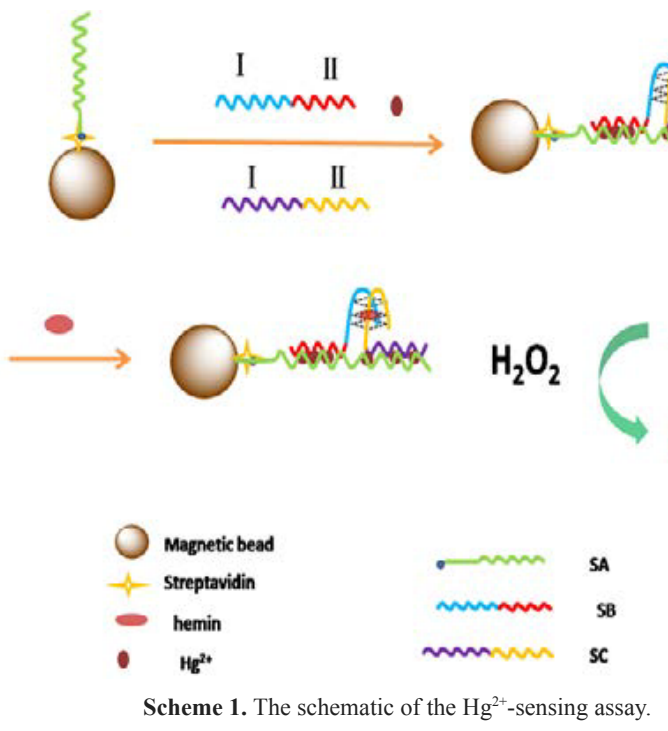

Table 1. Nucleic acid sequences.

\begin{tabular}{|c|l|}
\hline Name & \multicolumn{1}{|c|}{ Sequences } \\
\hline SA1 & 5'-CTTGCTCGGTTCGCTC-3' \\
\hline SB1 & 5'-GGGTTGGGACCGTGCTTG-3' \\
\hline SC1 & 5'-GTGCGTTCACGGGTAGGG-3' \\
\hline SA2 & 5'-CTTGCTCTTCTCGTTC-3' \\
\hline SB2 & 5'-GGGTTGGGACTGTGCTTG-3' \\
\hline SC2 & 5'-GTTCGTGTACGGGTAGGG-3' \\
\hline SA3 & 5'-GTTGCTCCCTCCGCTCGTTCGTGG-3' \\
\hline SB3 & 5'-GGGTTGGGACGGTGGGTGCTTC-3' \\
\hline SC3 & 5'-CCTCGTTCGTGCACGGGTAGGG-3' \\
\hline SA4 & 5'-TCTGCTTGCTGTTCGTGTTC-3' \\
\hline Biotin-SA4 & 5'-biotin-C20-TCTGCTTGCTGTTCGTGTTC-3' \\
\hline -SA4 & 'GTTCGTGTTC-3' \\
\hline SB4 & 5'-GGGTTGGGACTGCTTGCTGT-3' \\
\hline SC4 & 5'-GTTCTCGTTCACGGGTAGGG-3' \\
\hline
\end{tabular}

\section{Preparation of strand A modified MNPs}

An $100 \mu \mathrm{L}$ solution of streptavidin coated MNPs (diameter $100 \mathrm{~nm}$, $10 \mathrm{mg} / \mathrm{ml})$ was mixed with $100 \mu \mathrm{L}(5 \mu \mathrm{mol} / \mathrm{L})$ of biotin-SA4 and 100 $\mu \mathrm{L}$ of SSC (Saline sodium citrate) buffer. After $2 \mathrm{~h}$ of incubation with gentle shaking at $37^{\circ} \mathrm{C}$, the mixture was washed three times with SSC buffer to remove redundant SA. A 2\% BSA solution was used to block the MNPs surface and eliminate further nonspecific adsorption, and then, $1 \mathrm{~h}$ of blocking treatment was settled. The MNPs-SA were finally stored in $200 \mu \mathrm{L}$ of $\mathrm{Hg}^{2+}$ capture buffer at $4^{\circ} \mathrm{C}$ for further use.

\section{Circular dichroism spectroscopy measurements}

Briefly, a mixed solution of $10 \mu \mathrm{L}$ of $0.12 \mathrm{mmol} / \mathrm{L} \mathrm{SA}, 10 \mu \mathrm{L}$ of 0.12 $\mathrm{mmol} / \mathrm{L} \mathrm{SB}, 10 \mu \mathrm{L}$ of $0.12 \mathrm{mmol} / \mathrm{L} \mathrm{SC}$ and $80 \mu \mathrm{L}$ of capture buffer was heated at $90^{\circ} \mathrm{C}$ for $5 \mathrm{~min}$. Then, $8 \mathrm{nmol}$ mercury ions mixed with 25 $\mu \mathrm{L}$ of $200 \mathrm{mmol} / \mathrm{L} \mathrm{KAc}$ were added, and the solution was diluted to $400 \mu \mathrm{L}$ with $2 \times$ HEPES buffer. After incubation at $37^{\circ} \mathrm{C}$ for $4 \mathrm{~h}$, the $\mathrm{CD}$ measurement was performed on a JASO J-815 spectropolarimeter with a $2 \mathrm{~nm}$ bandwidth and $100 \mathrm{~nm} / \mathrm{min}$ scan speed.

\section{$\mathrm{Hg}^{2+}$ recognition}

A solution of $15 \mu \mathrm{L}$ of $5 \mu \mathrm{mol} / \mathrm{L}$ SB4, $15 \mu \mathrm{L}$ of $5 \mu \mathrm{mol} / \mathrm{L}$ SC4, 30 $\mu \mathrm{L}$ of $5 \mathrm{mg} / \mathrm{mL}$ MNPs-SA4, $100 \mu \mathrm{L}$ of $\mathrm{Hg}^{2+}$ capture buffer, $125 \mu \mathrm{L}$ of $200 \mathrm{mmol} / \mathrm{L} \mathrm{KAc}$ and various concentrations of the $\mathrm{Hg}^{2+}$ solution were mixed thoroughly. The volume of the solution was fixed to $500 \mu \mathrm{L}$ by the addition of $2 \times$ HEPES buffer, and then it was incubated with gentle shaking at $37^{\circ} \mathrm{C}$ for $4 \mathrm{~h}$ to form intermolecular split G-quadruplex DNAzymes. After that, $5 \mu \mathrm{L}$ of $5 \mu \mathrm{mol} / \mathrm{L}$ hemin was added, and the mixture was reacted at the same conditions for 40 minutes. Finally, the complex was separated from the mixture solution, washed with $2 \times$ HEPES buffer twice and then resuspended in $440 \mu \mathrm{L}$ of $2 \times$ HEPES buffer for colorimetric measurement.

\section{Colorimetric measurements}

Fifty microliters of $40 \mathrm{mmol} / \mathrm{L}$ ABTS and $10 \mu \mathrm{L}$ of $59 \mu \mathrm{mol} / \mathrm{L} \mathrm{H}_{2} \mathrm{O}_{2}$ were added into the above buffer. The absorption spectrum of $\mathrm{ABTS}^{+}$ was measured at $421 \mathrm{~nm}$. The equation $\Delta \mathrm{A}_{421 \mathrm{~nm}}=\mathrm{A}_{421 \mathrm{~nm}}-\mathrm{A}_{0}$ was used for quantitative analysis, in which $\mathrm{A}_{0}$ indicates the background absorption.

\section{Results and discussion}

\section{Design of the $\mathrm{Hg}^{2+}$-sensing assay}

To validate the mechanism of the developed $\mathrm{Hg}^{2+}$-sensing assay, 
the peroxidising activities of hemin, MNPs-SA4, and the mixtures of MNP-SA4, SB4, SC4 and hemin with and without $\mathrm{Hg}^{2+}$ were compared in the ABTS- $\mathrm{H}_{2} \mathrm{O}_{2}$ system. As shown in Figure 1, curve a presents the absorption of ABTS. Although hemin is thegood catalyzer, the free form of hemin would be eliminated by washing step; therefore, a lower catalytic curve has been observed (curves b). MNPs-SA4 showed inherently low catalytic activities, and ABTS cannot be oxidised by hydrogen peroxide under the usual conditions (curves $c$ ). When the component DNAzyme strands SB and SC were added, the system exhibited just a little higher peroxidising activity, demonstrating that the free forms of SB and SC in solution could not construct a stable G-quadruplex to catalyse the oxidation of ABTS (curve d). In the presence of $\mathrm{Hg}^{2+}$, the absorption signal at $421 \mathrm{~nm}$ rose sharply, indicating that the oxidation of ABTS was violently catalysed by the intermolecular split DNAzyme. The increase in the absorbance $\left(\mathrm{A}_{421 \mathrm{~mm}}\right)$ in curve e is the result of the hybridisation between SA, SB and SC by $\mathrm{T}-\mathrm{Hg}^{2+}-\mathrm{T}$ to construct the sandwich system forcing both the G-rich ends of SB and SC close together to form a very stable catalytically active G-quadruplex-hemin DNAzyme, demonstrating that the formation of a sandwich in the presence of $\mathrm{Hg}^{2+}$ is the key to the $\mathrm{Hg}^{2+}$ sensor. This result successfully suggests the feasibility of the $\mathrm{Hg}^{2+}$-sensing protocol mentioned in Scheme 1.

Experimental conditions: $[\mathrm{ABTS}]=4 \mathrm{mM},\left[\mathrm{H}_{2} \mathrm{O}_{2}\right]=1.2 \mu \mathrm{M},\left[\mathrm{Hg}^{2+}\right]$ $=100 \mathrm{nM}$, [hemin $]=50 \mathrm{nM}$, [MNPs-SA4] $=150 \mu \mathrm{g}$, [SB4] $=150 \mathrm{nM}$, and $[\mathrm{SC} 4]=150 \mathrm{nM}$. All of the spectra were collected at $8 \mathrm{~min}$ after the catalytic reaction.

It is imperative for the proposed $\mathrm{Hg}^{2+}$ sensing strategy to demonstrate that without the target $\mathrm{Hg}^{2+}$, the free forms of $\mathrm{SB}$ and SC would not construct the G-quadruplex even in a semi-stable state, which would result in a high background and false response. To meet this requirement, four versions of $\mathrm{SA}, \mathrm{SB}$, and SC with different base sequences and lengths were carefully designed to ensure that the intermolecular split G-quadruplex DNAzyme was constructed only in the presence of $\mathrm{Hg}^{2+}$. As shown in Figure 2, the black bars, sparse bars and dense bars represent the absorption signal of free hemin, the mixture of the MNPs-SA, SB, SC, and hemin with and without $\mathrm{Hg}^{2+}$, respectively. All dense bars in Figure 2 were a little higher than the black bars to

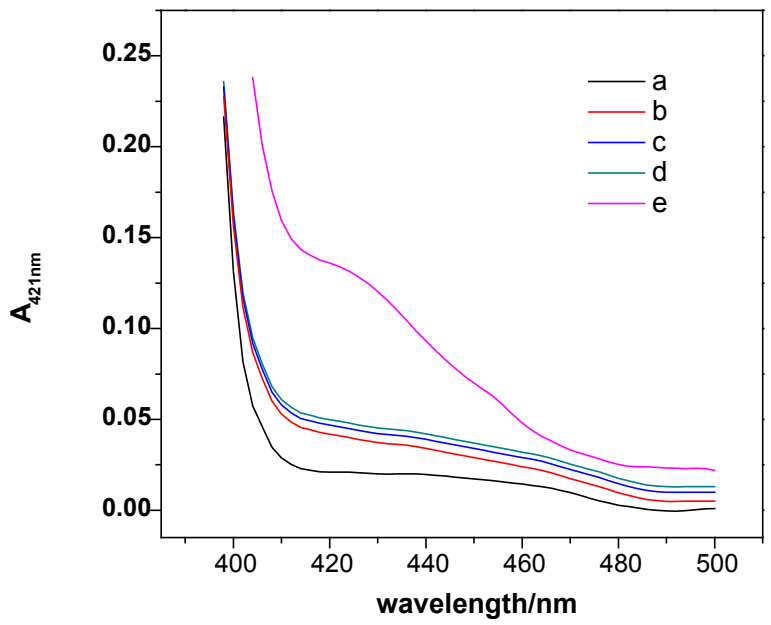

Figure 1. The catalysis spectral curves of ABTS (a), MNPs-SA4 (b), hemin (c), a mixture of MNPs-SA4, SB4, SC4 and hemin with (e) and without (d) $\mathrm{Hg}^{2+}$. Experimental conditions: $[\mathrm{ABTS}]=4 \mathrm{mM},\left[\mathrm{H}_{2} \mathrm{O}_{2}\right]=1.2 \mu \mathrm{M},\left[\mathrm{Hg}^{2+}\right]=100 \mathrm{nM},[$ hemin $]=50 \mathrm{nM},[$ MNPs-SA4 $]=$ $150 \mu \mathrm{g},[\mathrm{SB} 4]=150 \mathrm{nM}$, and $[\mathrm{SC} 4]=150 \mathrm{nM}$. All of the spectra were collected at 8 min after the catalytic reaction.

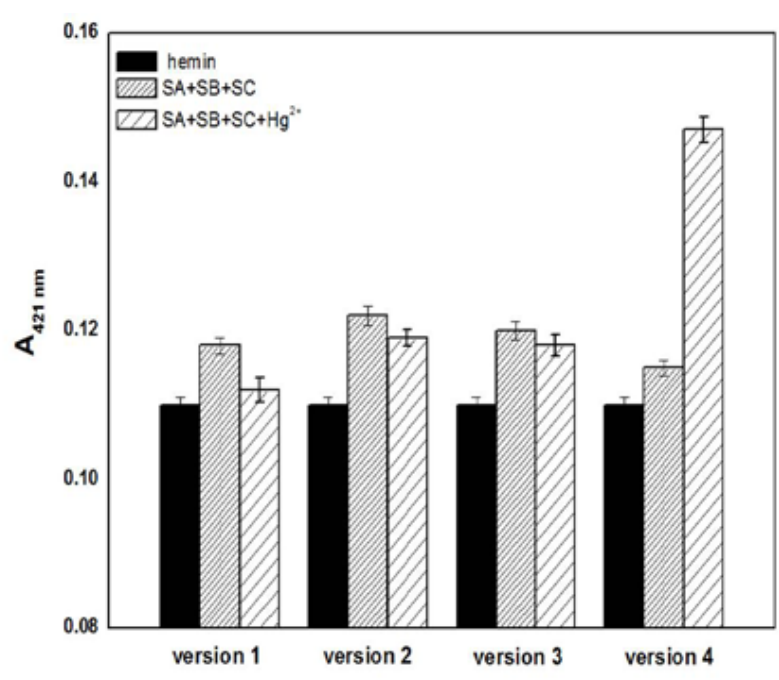

Figure 2. The absorption signals of free hemin (black bars) and the sensor solution in the absence (dense bars) or presence (sparse bars) of $\mathrm{Hg}^{2+}$ when different strand sequences were used. Experimental conditions: $[\mathrm{ABTS}]=4 \mathrm{mM},\left[\mathrm{H}_{2} \mathrm{O}_{2}\right]=1.2 \mu \mathrm{M},[$ hemin $]=50 \mathrm{nM},\left[\mathrm{Hg}^{2+}\right]$ $=100 \mathrm{nM},[\mathrm{SA}]=150 \mathrm{nM},[\mathrm{SB}]=150 \mathrm{nM}$, and $[\mathrm{SC}]=150 \mathrm{nM}$.

different extents, exhibiting the liable G-quadruplex might be formed in the absence of mercury ions. The complementary G-C base pair of the SA strands between their corresponding SB or SC are 50\% (version 2 and 4 ), $62.5 \%$ (version 1) and $66.7 \%$ (version 3), which can incline SB and SC to become close to each other by partial hybridisation and the formation of an unstable G-quadruplex. Except for the fourth version, all of the absorbance signals in the presence of $\mathrm{Hg}^{2+}$ (sparse bars) were slightly lower than the signals without $\mathrm{Hg}^{2+}$ (dense bars), indicating that the lesion of the intermolecular split DNAzymes occurred due to the intercalation of mercury ions loosening the G-quardruplex. The sparse bar of version 4 , which is much higher than the signals of free hemin and the mixture without $\mathrm{Hg}^{2+}$, indicates that only the fourth version is consistent with the $\mathrm{Hg}^{2+}$-sensing mechanism as we expected. In four versions, the shortest strands are the SA1 and SA2 strands, both of them having 16 bases, and SA3 is the longest with 24 bases, while the SA4 is in the middle with 20 bases (Table 1). The rise of the sparse bar in version 4 demonstrates that the liable state G-quadruplex DNAzymes would be stabilised in the presence of mercury ions with the strands of the sandwich (SA, SB and SC) having a suitable number of G/C and T-T mismatched bases in the appropriate length.

The results of the previous three versions indicate that the formation of split DNAzymes and their catalytic activities were heavily influenced by the characters (sequence and length) of the strands (SA, SB and SC). Therefore, CD spectroscopy was used to further test this hypothesis on account of each type of DNA strand possessing its own special CD spectrum (Figure 3). It has been reported that a positive CD signal at $263 \mathrm{~nm}$ and a negative one at $240 \mathrm{~nm}$ are characteristics of a parallel conformer[17]. As shown in Figure 3(C), both the CD spectra of the SA, SB and SC mixture and the mixture with $\mathrm{Hg}^{2+}$ displayed a positive peak at approximately $260 \mathrm{~nm}$ and a negative peak at approximately $240 \mathrm{~nm}$, suggesting that the parallel G-quadruplex was formed and exhibited a higher peroxidative activity, which is consistent with the UV-vis absorption signal (Figure 2, column 3). The CD spectra of versions 1 (Figure 3A), 2 (Figure 3B) and 4 (Figure 3D) visualise completely different from the CD spectrum of the third version. All of them exhibit two positive peaks at approximately 260 and $290 \mathrm{~nm}$ and a negative peak at approximately $240 \mathrm{~nm}$. It is said that if there is a 

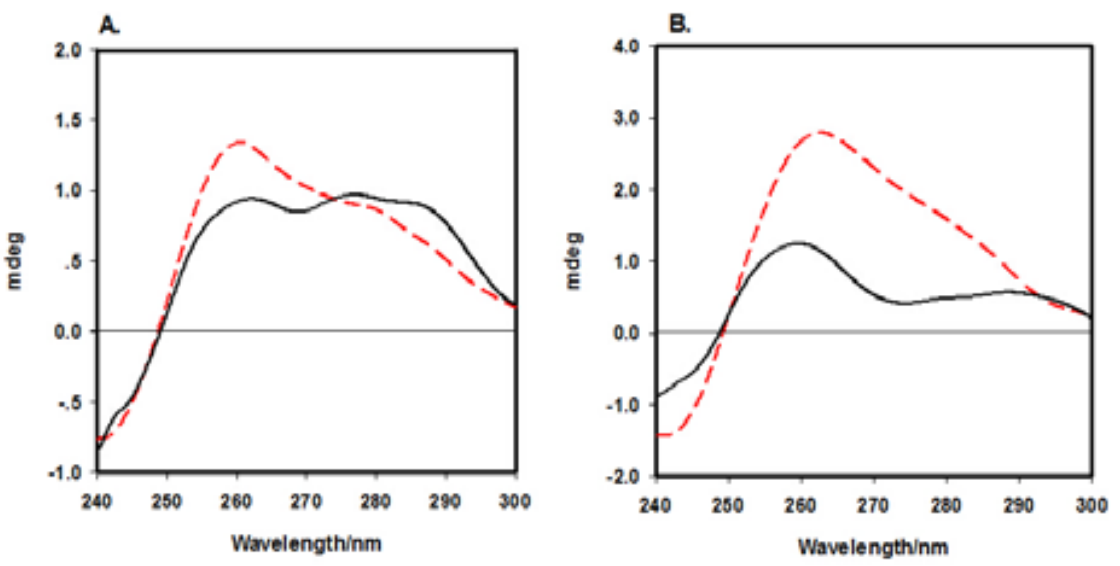

c.

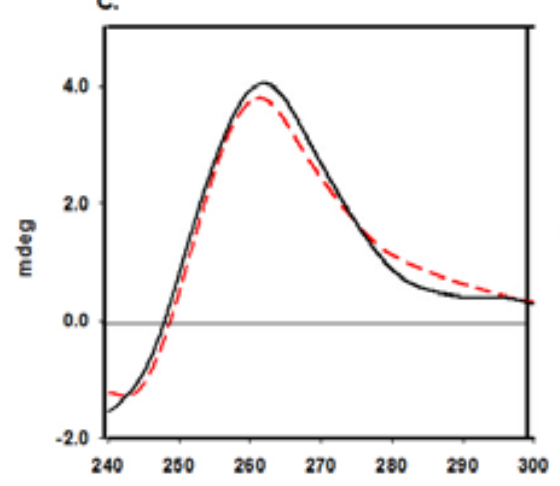

D.

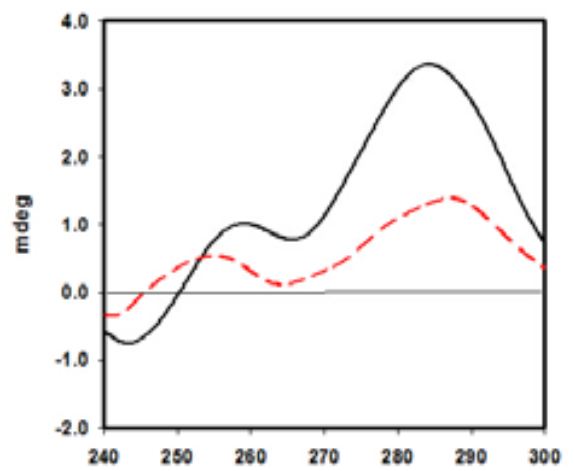

Figure 3. The CD spectra of system SA1/SB1/SC1 (A), system SA2/SB2/SC2 (B), system SA3/SB3/SC3 (C) and system SA4/SB4/SC4 (D) in the absence (red dashed lines) and presence of $\mathrm{Hg}^{2+}$ ions (black solid curves). Experimental conditions: $[\mathrm{SA}]=3 \mu \mathrm{M},[\mathrm{SB}]=3 \mu \mathrm{M},[\mathrm{SC}]=3 \mu \mathrm{M}$ and $\left[\mathrm{Hg}^{2+}\right]=20 \mu \mathrm{M}$.

small positive peak at $265 \mathrm{~nm}$ along with a negative peak approximately $240 \mathrm{~nm}$ and a stronger positive peak at $295 \mathrm{~nm}$, the version may be characterised as a hybrid of parallel/antiparallel structures $[12,18,19]$. Therefore, the conformations of the G-quadruplex split DNAzymes in these three versions are mixtures of parallelism and anti-parallelism. The CD signals (solid lines in Figure $3 \mathrm{~A}$ and $\mathrm{B}$ ) reduced accordingly in the presence of $\mathrm{Hg}^{2+}$, partly because of the liable state G-quadruplex structures being gradually decomposed with the addition of $\mathrm{Hg}^{2+}$, which weakened the catalytic activity of the system. As shown in Figure 3D, the CD signals (solid line) were obviously higher than the signals of the dashed line, reflecting the perfect formation of the stable catalytically active G-quadruplex DNAzymes. The results obtained from the above experiments make it clear that only the fourth version exhibited a high catalytic peroxidative activity with the addition of $\mathrm{Hg}^{2+}$.

The interaction between SB and SC was also introduced to illustrate the inherent catalytic activity of the system in the absence of $\mathrm{Hg}^{2+}$. In the former three versions, there are many complementary base pairs (e.g., G-C, A-T) between SB and SC (Figure S1A, 1B and 1C see supplementary content), and their binding affinities $(\Delta \mathrm{Gs})$ as well as melting temperatures $\left(\mathrm{T}_{\mathrm{m}}\right)$ are both high (Table $\mathrm{S} 1$ ), suggesting that they could partly hybridise with each other. It has been reported that a nucleic acid strand possessing four, or more than four, poly (dG) domains can construct the intramolecular G-quadruplex [13, 20]; however, only two poly $(\mathrm{dG})$ domains in those versions of SB or SC cause the formation of intermolecular G-quadruplexes instead of by the association of SB and SC. Therefore, the mixture of SA, SB, $\mathrm{SC}$, and hemin without mercury ions in the former three versions showed an enhanced peroxidative activity. While with the addition of $\mathrm{Hg}^{2+}$, the liable state G-quadruplex-hemin DNAzymes in these three versions cannot be further stabilised due to that the number of the T-T mismatches verses the length of the SA strands was too few. Whereas, in the fourth version (Figure S1D), the complementary base pairs (e.g., G-C, A-T) of the hybridised SB4 and SC4 is few, and their binding affinity $(\Delta \mathrm{G})$ and melting temperature (Tm) are low (Table S1), indicating that the interaction between SB and SC is very weak. Moreover, there are adequate numbers of $\mathrm{T}-\mathrm{T}$ mismatches between $\mathrm{SA}$ and $\mathrm{SB} / \mathrm{SC}$ to constitute duplexing by $\mathrm{T}-\mathrm{Hg}^{2+}-\mathrm{T}$, and stable G-quadruplex intermolecular DNAzymes form so that the MNPs-SA4/ SB4/SC4/hemin system could express the supernal peroxidative activity in the presence of $\mathrm{Hg}^{2+}$. All of the above results validated that if positive responses are required, the low affinity between the component strands of the intermolecular split G-quadruplex should be encouraged and complementary bases between them should be avoided.

\section{Optimisation of the experimental parameters}

The experimental parameters (e.g., the capture time of $\mathrm{Hg}^{2+}$ and the concentration of $\mathrm{K}^{+}$) that could affect the analytical performance and results were optimised. Data on the capture time over the range from 1 to $6 \mathrm{~h}$ at room temperature were obtained (Figure S2). These data reveal that the $\Delta \mathrm{A}_{421 \mathrm{~nm}}$ of the supernatant increases sharply as the capture time increases up to $4 \mathrm{~h}$ and remains stable for another two hours. Another factor taken into account for the parameter optimisation is the concentration of $\mathrm{K}^{+}$. In general, G-quadruplex structures can be stabilised by alkali cations such as $\mathrm{K}^{+}$and $\mathrm{Na}^{+}[21]$. It has been proven that $\mathrm{K}^{+}$is absolutely required for the catalytic behaviour of the heminPS2M complex and has the highest efficiency for coordination to the 
G-quadruplex[22]. Therefore, in our work, the dosage of $\mathrm{K}^{+}$should be carefully selected. The $\Delta \mathrm{A}_{421 \mathrm{~nm}}$ first increased along with the increase of $\mathrm{K}^{+}$and reached a plateau at approximately $50 \mathrm{mmol} / \mathrm{L}$. Then, it sharply decreased as the concentration of $\mathrm{K}^{+}$continued to increase (Figure S3). This suggests that $\mathrm{K}^{+}$could strengthen the stability of the intermolecular split of the G-quadruplex DNAzymes in a certain range, while also promoting the catalytic behaviour of the DNAzymes.

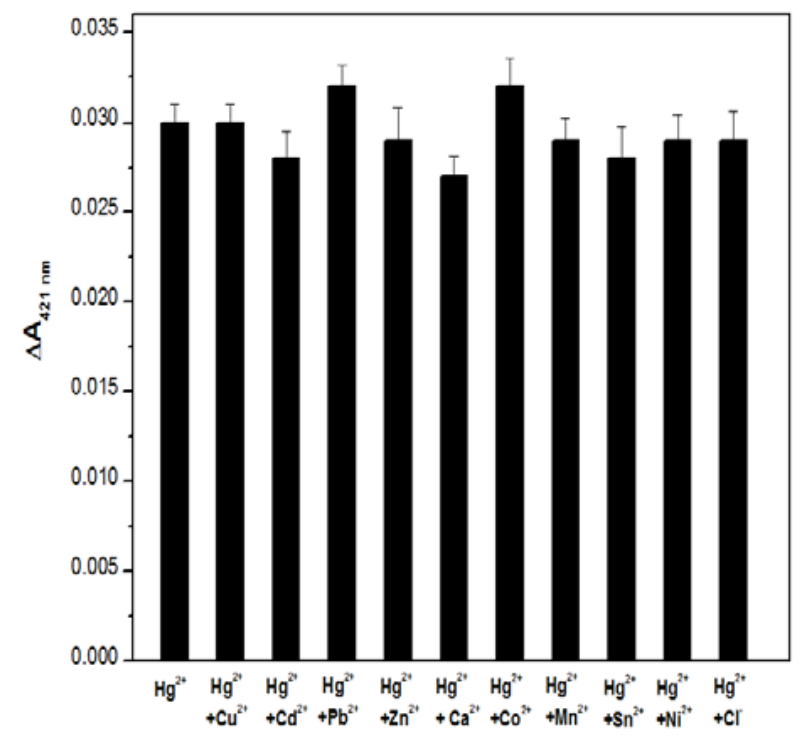

Figure 4. The selectivity of the $\mathrm{Hg}^{2+}$-sensing assay in the presence of $25 \mathrm{nM} \mathrm{Hg}^{2+}$ and 2.5 $\mu \mathrm{M}$ other ions, while the concentration of $\mathrm{Cl}^{-}$is $0.25 \mathrm{mM}$.

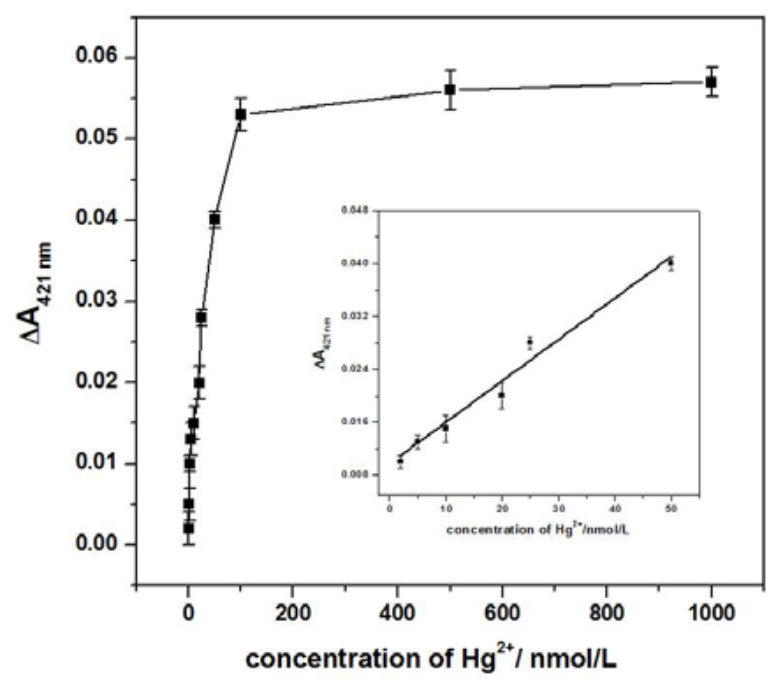

Figure 5. The calibration curve corresponding to the $\Delta \mathrm{A}_{421 \mathrm{~nm}}$ of the $\mathrm{Hg}^{2+}$ sensing assay with different $\mathrm{Hg}^{2+}$ concentrations after $10 \mathrm{~min}$ of catalytic reaction. The inset presents the amplification of the linear range from $2 \mathrm{nM}$ to $50 \mathrm{nM}$.

Table 2. Results of the actual samples*.
Therefore, 4 hours of capture time and $50 \mathrm{mmol} / \mathrm{L}$ of $\mathrm{K}^{+}$were chosen as the optimal parameters.

\section{Selectivity of the $\mathrm{Hg}^{2+}$-sensing assay}

To test the selectivity of the proposed $\mathrm{Hg}^{2+}$-sensing assay, control experiments were executed to evaluate whether other environmentally relevant metal ions performed similar functions as the $\mathrm{Hg}^{2+}$ in the current biosensor. Thus, $2.5 \mu \mathrm{M}$ aliquots of other metal ions including $\mathrm{Zn}^{2+}, \mathrm{Pb}^{2+}, \mathrm{Cd}^{2+}, \mathrm{Mn}^{2+}, \mathrm{Ca}^{2+}, \mathrm{Co}^{2+}, \mathrm{Sn}^{2+}, \mathrm{Ni}^{2+}$ and $\mathrm{Cl}^{-}$were added individually or in combination to the detection solution together with $25 \mathrm{nM} \mathrm{Hg}^{2+}$. The $\Delta \mathrm{A}_{421 \mathrm{~nm}}$ signal was measured, and the results are presented in Figure 4. It shows that all of the other metal ions presented only slight effects on the UV-Vis absorption of the sensing system, indicating that the sensing assay described herein exhibits a high specificity for $\mathrm{Hg}^{2+}$ against other metal ions.

\section{Quantitative detection of mercury ions}

In the quantitative analysis, the prepared sensing assay was incubated with different amounts of $\mathrm{Hg}^{2+}$ under the optimal conditions to obtain a calibration curve. The data in Figure 5 show that with increasing concentrations of $\mathrm{Hg}^{2+}$, the $\Delta \mathrm{A}_{421 \mathrm{~nm}}$ signals obviously increased. A linear response was obtained for $\mathrm{Hg}^{2+}$ concentrations ranging from $2 \mathrm{nM}$ to $50 \mathrm{nM}$, according to the equation $\Delta \mathrm{A}_{421 \mathrm{~nm}}=$ $9.17 \times 10^{-3}+6.26 \times 10^{-4} \mathrm{C}_{\mathrm{Hg} 2+}(\mathrm{nM})$ with a correlation coefficient 0.9890 and a P-value 0.023 at the $95 \%$ confidence level. The detection limit of 0.8 $\mathrm{nM}$ was obtained by evaluating the average response of the blank plus three times the standard deviation. Such a result was more sensitive than the colorimetric biosensor $[23,24]$ and electrochemical methods [25] for $\mathrm{Hg}^{2+}$ detection. According to the reference values, which are supplied by American government, the limit for the concentration of $\mathrm{Hg}^{2+}$ in drinking water is $10 \mathrm{nM}$. Given the sensitivity and specificity of this method, we expect that it will be a promising tool for practical $\mathrm{Hg}^{2+}$ analysis.

\section{Application to sample analysis}

To validate the practical application of our proposed method, several environmental water samples including industrial waste water, tap water and lake water were analysed using the proposed $\mathrm{Hg}^{2+}$-sensing assay. Furthermore, samples spiked with a certain amount of $\mathrm{Hg}^{2+}$ were detected according to the general procedure with three replicates. The results are shown in Table 2. Satisfactory recovery values between 95.0 and $106.0 \%$ demonstrated that the biosensor system can be successfully applied to $\mathrm{Hg}^{2+}$ analysis in real environmental samples.

\section{Conclusions}

In summary, a colorimetric method for the detection of aqueous $\mathrm{Hg}^{2+}$ was established based on intermolecular split G-quadruplex DNAzymes and magnetic nanoparticles. Compared with non-split DNAzymes, the employment of intermolecular split DNAzymes made the design of the experiment more flexible. The aforementioned experiments have shed light on the important architectural features of split G-quadruplex DNAzymes required. In our work, several key

\begin{tabular}{|c|c|c|c|c|c|}
\hline Sample & $\mathrm{Hg}^{2+}$ measured $(\mathrm{nmol} / \mathrm{L})$ & CVAAS (nmol/L)** & Addition of $\mathrm{Hg}^{2+}(\mathrm{nmol} / \mathrm{L})$ & Detection of $\mathrm{Hg}^{2+}(\mathrm{nmol} / \mathrm{L})$ & Recovery(\%) \\
\hline running water & not detected & not detected & 20.0 & 19.0 & 95.0 \\
\hline river water & not detected & not detected & 20.0 & 20.7 & 103.5 \\
\hline industrial wastewater & 4.6 & 4.8 & 15.4 & 21.2 & 106.0 \\
\hline
\end{tabular}

* All data in the table were the average of three independent experiments.

** The data were obtained by cold vapor atomic absorption spectrometry. 
factors such as the base sequences and lengths of the component strands of the split G-quadruplex have been discussed. It was determined that the intermolecular split DNAzymes and their catalytic activity were heavily influenced by such characteristics. We have suggested that more complementary bases and a higher affinity between the free forms of strand $\mathrm{B}$ and $\mathrm{C}$ would damage the design of the nanoparticles as carriers of the recognising strands would remove other co-existing interfering ions and minimise the background. This assay enabled the sensitive and selective detection of $\mathrm{Hg}^{2+}$. The sensing assay can also be applied in practical aqueous systems to determine the content of $\mathrm{Hg}^{2+}$. Given the sensitivity and specificity of this method, we expect that it will be a promising tool for practical $\mathrm{Hg}^{2+}$ analysis.

\section{Acknowledgement}

This work was supported by the National Nature Science Foundation of China (Grant no. 21175045, 21275054) and the Ministry of Science and Technology (Grant no. 2011YQ150078).

\section{References}

1. Nolan EM, Lippard SJ (2008) Tools and tactics for the optical detection of mercuric ion. Chem Rev 108: 3443-3480. [crossref]

2. Magos L, Clarkson TW (2006) Overview of the clinical toxicity of mercury. Ann ClinBiochem43: 257-268. [crossref]

3. Cotton F, Wilkinson G, Murillo C, Bochmann M (1999) Advanced Inorganic Chemistry Wiley. New York 598-629.

4. Zhang WB, Su ZF, Chu XF, Yang XA (2010) Evaluation of a new electrolytic cold vapor generation system for mercury determination by AFS. Talanta80: 2106-2112. [crossref]

5. Gao Y, Shi M, Long Z, Wu P,Zheng C,Hou X (2012) Determination and speciation of mercury in environmental and biological samples by analytical atomic spectrometry. Microchemical Journal, 103: 1-14.

6. Chen B,Heng S, Peng H,Hu B,Yu X, et al. (2012) Magnetic solid phase microextraction on a microchip combined with electrothermal vaporization-inductively coupled plasma mass spectrometry for determination of $\mathrm{Cd}, \mathrm{Hg}$ and $\mathrm{Pb}$ in cells. Journal of Analytical Atomic Spectrometry: 25.

7. Kong DM, Wu J, Wang N, Yang W, Shen HX (2009) Peroxidase activity-structure relationship of the intermolecular four-stranded G-quadruplex-hemin complexes and their application in $\mathrm{Hg} 2+$ ion detection. Talanta 80: 459-465.

8. Kavitha R, Stalin T (2014) A highly selective chemosensor for colorimetric detection of $\mathrm{Hg} 2+$ and fluorescence detection of $\mathrm{pH}$ changes in aqueous solution. Journal of Luminescence 149: 12-18.

9. Ge J, Li XP, Jiang JH,Yu RQ (2014) A highly sensitive label-free sensor for Mercury ion $(\mathrm{Hg} 2+)$ by inhibiting thioflavin T as DNA G-quadruplexes fluorescent inducer. Talanta 122: 85-90.
10. Li C, Dai P, Rao X, Shao L, Cheng G, He P, Fang Y (2015) An ultra-sensitive colorimetric $\mathrm{Hg} 2+$-sensing assay based on DNAzyme-modified Au NP aggregation, MNPs and an endonuclease. Talanta 132: 463-468.

11. Zhang J (2014) A Symmetrically Split G-quadruplex DNAzymes Biosensor Based on Magnetic Nanoparticles for the Rapid Detection of Hg2+. Acta ChimSinica 72: 10291035

12. Nakayama S, Sintim HO (2009) Colorimetric Split G-Quadruplex Probes for Nucleic Acid Sensing: Improving Reconstituted DNAzyme's Catalytic Efficiency via Probe Remodeling. Journal of the American Chemical Society 131: 10320-10333.

13. Deng M, Zhang D, Zhou Y, Zhou X (2008) Highly effective colorimetric and visual detection of nucleic acids using an asymmetrically split peroxidase DNAzyme. Journal of the American Chemical Society 130: 13095-13102.

14. Li T, Wang E, Dong S (2009) Base-pairing directed folding of a bimolecular G-quadruplex: new insights into G-quadruplex-based DNAzymes. Chemistry 15: 20592063. [crossref]

15. Kong DM, Cai LL, Shen HX (2010) Quantitative detection of $\mathrm{Ag}(+)$ and cysteine using G-quadruplex-hemin DNAzymes. Analyst 135: 1253-1258. [crossref]

16. Kong DM, Wang N, Guo XX, Shen HX (2010) 'Turn-on' detection of Hg2+ ion using a peroxidase-like split G-quadruplex-hemin DNAzyme. Analyst 135: 545-549. [crossref]

17. Jin R, Gaffney BL, Wang C, Jones RA, Breslauer KJ (1992) Thermodynamics and structure of a DNA tetraplex: a spectroscopic and calorimetric study of the tetramolecular complexes of d(TG3T) and d(TG3T2G3T). Proceedings of the National Academy of Sciences of the United States of America 89: 8832-8836.

18. Wang Y, Patel DJ (1993) Solution structure of the human telomeric repeat AG3(T2AG3)3 G-tetraplex, Structure (London, England : 1993) 1: 263-282.

19. Ambrus A, Chen D, Dai DX, Bialis T, Jones RA, Yang DZ (2006) Human telomeric sequence forms a hybrid-type intramolecular G-quadruplex structure with mixed parallel/antiparallel strands in potassium solution, Nucleic Acids Research 34: 27232735 .

20. Gellert M, Lipsett MN, Davies DR (1962) Helix formation by guanylic acid. Proc Natl Acad Sci U S A 48: 2013-2018. [crossref]

21. Sen D, Gilbert W (1990) A sodium-potassium switch in the formation of four-stranded G4-DNA. Nature 344: 410-414. [crossref]

22. Travascio P, Li Y, Sen D (1998) DNA-enhanced peroxidase activity of a DNA-aptamerhemin complex. Chem Biol 5: 505-517. [crossref]

23. Zhu D, Luo J, Rao X, Zhang J, Cheng G, et al. (2012) A novel optical thrombin aptasensor based on magnetic nanoparticles and split DNAzyme. Anal Chim Acta 711 91-96. [crossref]

24. Wu J,Li L,Zhu D,He P,Fang Y,Cheng G (2011) Colorimetric assay for mercury (II) based on mercury-specific deoxyribonucleic ac-id-functionalized gold nanoparticles AnalyticaChimica Acta 694: 115-119.

25. Wu J,Li L, Shen B, Cheng G, He P,Fang Y (2010) Polythymine OligonucleotideModified Gold Electrode for VoltammetricDetermina-tion of Mercury (II) in Aqueous Solution Electroanalysis 22: 479-482.

Copyright: (C2016 Zhang W. This is an open-access article distributed under the terms of the Creative Commons Attribution License, which permits unrestricted use, distribution, and reproduction in any medium, provided the original author and source are credited. 